DOI: $10.7242 / 2658-705 X / 2019.4 .8$

УДК 324

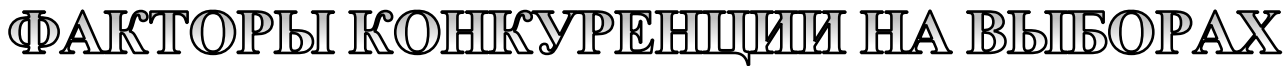

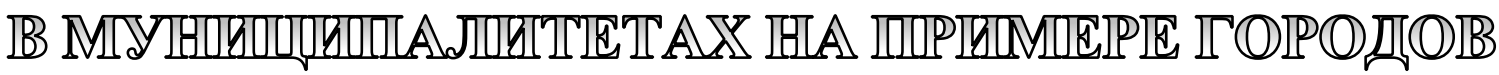

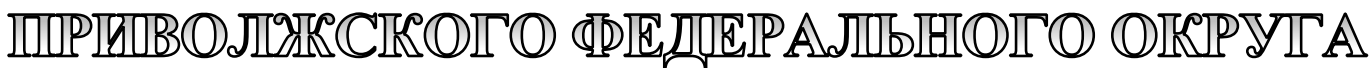

\section{У.И. Чадова, Пермский федеральный исследовательский центр УрО РАН}

Цель статьи - выявление фракторов, которые обусловливают наличие или отсутствие конкуренции на выборах в муниципалитетах. В работе обобщен теоретический материал существующих исследований феномена конкуренции как на федеральном и региональном, так и на муниципальном уровнях. Опираясь на сорормулированную теоретическую рамку, были выделены такие факторы, как качество жизни, этнический состав населения, доля населения пенсионного возраста, явка и доля зарегистрированных кандидатов-инкумбентов на выборах. Основное содержание исследования составляет качественный сравнительный анализ (QCA). Для анализа были взяты результаты выборов в представительные органы крупнейших городских округов и муниципальных районов Приволжского федерального округа за последний электоральный цикл. Проведенный анализ определил, что наличие политических машин на территориях с преобладанием этнического населения способствует низкой конкуренции. Также в работе были подтверждены утверждения о том, что высокая явка, преобладание кандидатовинкумбентов на выборах обусловливают низкий уровень конкуренции на выборах. Предположение о роли качества жизни в повышении конкуренции является противоречивым, так как оно не получило определенного результата в ходе работы. В то же время, выявленные фракторы являются неоднозначными, так как вследствие ограниченности эмпирических данных, вероятно, не были учтены значимые переменные.

Ключевые слова: муницииалитеты, выборы, конкуренциия.

\section{Введение}

На данный момент в России выстроена устойчивая «вертикаль власти», в рамках которой в политических процессах на местном уровне принимает активное участие региональная и федеральная власть. Такие процессы, как централизация, лишение экономической автономии, оказали влияние на все муниципальные образования. [5, с. 9-24] Исходя их этого, можно предполагать, что региональная и федеральная власти имеют существенное влияние на электоральные процессы в рамках муни- ципалитета. В то же время помимо внешнего воздействия, стоит рассматривать и внутренние характеристики территории, например, такие как уровень благосостояния граждан, этнический и поло-возрастной состав населения, поведение граждан на выборах (явка) и т.д., которые также влияют на выборы в муниципалитетах.

Также, на муниципальном уровне остаются различия в уровне конкуренции на выборах, несмотря на то, что доминирующая партия «Единая Россия» получает большинство мандатов. Так, в Тольят- 
ти на выборах депутатов Городского совета в 2018 году «партия власти» получила 100\% мандатов, а показатель конкурентности на выборах равен 2,29, в Перми на выборах депутатов Городской думы в 2016 году «ЕР» получила 91\% мест, остальные места получили самовыдвиженцы (уровень конкуренции равен $2,74)$, в то же время в Городском округе Уфа «Единая Россия» получила 71\% мандатов, а уровень конкуренции составил $2,40^{1}$ [13]. Несмотря на то, что «партия власти» в данных примерах получает абсолютное большинство мандатов, конкуренция на выборах в представительные органы присутствует и не зависит напрямую от успехов «Единой России». Возникает закономерный вопрос: какие факторы влияют на уровень конкуренции в муниципальных образованиях?

Целью исследования и является выявление факторов, которые обусловливают наличие или отсутствие конкуренции на выборах в представительные органы муниципалитетов Приволжского федерального округа в период с 2014 по 2018 год.

В качестве метода исследования за основу взят метод качественного сравнительного анализа.

В исследовании рассмотрены города Приволжского федерального округа, так как в данном округе присутствуют различные вариации результатов выборов в представительные органы. Это муниципальные единицы по примерно равной численности населения (более 500 тысяч человек), а также административные центры. В них вошли города-миллионники и крупнейшие города. Численность определена на основании данных Всероссийской переписи населения 2010 года. Исходя из этого, в исследовании будут рассматриваться такие города, как Уфа, Нижний Новгород, Оренбург, Пенза, Пермь, Тольятти, Саратов, Казань, Набе- режные Челны, Ижевск и Ульяновск, Йошкар-Ола, Саранск, Чебоксары, Киров.

В качестве ответа на этот вопрос можно сказать, что преобладание этнического населения, способствует низкому уровню конкуренции. При этом высокая явка обусловливает низкий уровень конкуренции на выборах. Можно предположить, что уровень явки может быть искусственно завышен с помощью фальсификаций и \или мобилизации. Также выборы становятся менее конкурентными, если большая часть зарегистрированных кандидатов является инкумбентами. По итогу голосования, если наибольшее количество голосов получает кандидат-инкумбент, и уровень конкуренции является низким, то поддержка инкумбентов может обусловливаться теорией экономического голосования, так как уровень жизни является высоким.

\section{Обзор исследований и постановка проблемы}

А. Пшеворский писал, что демократия - это явление, при котором партии проигрывают выборы, а конкуренцию будет обеспечивать «определенность процедур при неопределенности результатов» [10]. Именно это определение указывает на важную роль конкуренции и на возможность малых и оппозиционных партий победить на выборах.

П. Мэйер писал о том, что необходимым условием для конкуренции являются избирательные правила, которые он называет структурами конкуренции. Существует два типа таких структур: закрытая и открытая. Закрытая структура предполагает собой предсказуемость результатов выборов, низкую вероятность включения в управление малых и новых, так как существует высокий порог для получения права принимать политические решения. Открытая структура характеризуется

\footnotetext{
${ }^{1}$ Данные взяты по мажоритарным округам.
} 
совершенно противоположными показателями: непредсказуемостью результатов, возможностью малым и новым, оппозиционным партиям принимать политические решения [21].

Существует множество исследований, в которых выделяются разные факторы, которые, по мнению авторов, влияют на конкуренцию. Можно предполагать, что на конкуренцию влияет наличие инкумбентов на выборах. Это следует из структурных условий, о которых писал П. Мэйер. В исследовании мы рассматриваем выборы по одномандатным округам, которые соответствуют закрытой структурой по типологии П. Мэйера, так как она зачастую не допускает новых кандидатов и позволяет выигрывать доминирующим игрокам.

Также, данное исследование опирается на теорию политических машин. Она предполагает, что там, где присутствует этническое население и/или большая доля населения старше трудоспособного возраста, работают политические машины, которые, как ожидается, снижают уровень конкуренции на выборах.

В. Воронцов писал о том, что в этнических республиках показатель уровня поддержки на выборах «Единой России» намного выше, чем в республиках, где подавляющую часть занимает русский этнос. [2, с. 391-392] Г. Хейл писал о том, что электоральные процессы - это рынок, в рамках которого происходит борьба за голоса с помощью предоставления населению определенных ресурсов. Эти ресурсы или блага конвертируют в голоса и обратно политические машины. Г. Хэйл отмечал, что политические машины наиболее эффективны там, где большая доля нерусского населения, небольшие и бедные территории, а также, там, где население пенсионного возраста превалирует над остальным и доминирует сельскохозяйственный сектор в экономике [19].

Политические машины оказывают влияние на конкуренцию на выборах не только в этнических регионах. Г. Хэйл также утверждал, что политические машины эффективны в тех регионах, где большую долю населения представляют люди пенсионного возраста [18]. С. Стоукс писала о том, что наиболее подвержены влиянию деятельности политических машин бедные территории [23]. В этой связи можем предположить, что по причине эффективной работы политических машин электоральная конкуренция может уменьшаться, наоборот, в бедных территориях.

На конкуренцию будет влиять и степень мобилизации электората, показателем которого является явка. Чем выше явка на выборах, тем, можно ожидать, ниже уровень конкуренции. На явку, по мнению Г. Голосова, влияет индивидуальное восприятие человеком выборов. Если общество понимает выборы как честные, то явка на них будет соответственно выше. При этом авторитарный контроль, даже в случае восприятия выборов как честных, может понизить явку из-за проявления абсентеизма со стороны оппозиционно настроенных избирателей [6]. Также явку исследовал А.Е. Любарев. Он определял тенденции изменения уровня явки на разных уровнях: федеральном, региональном и муниципальном. Общая тенденция снижения явки обусловливается, по его мнению, тем, что осуществляется целенаправленное препятствие участию оппозиционно настроенного населения в выборах, тем самым улучшая результаты «партии власти» [7]. При этом, как отмечает В. Гельман, следует учитывать, что там, где явка крайне высока, скорее всего, на выборах имела место быть фальсификация. В то же время, если явка низкая - это не говорит о честности выборов, а скорее о том, что граждане не заинтересованы в выборах и уверены в том, что результаты будут сфальсифицированы. С другой стороны, определенно, явка на выборах является показателем легитимности 
существующей власти, и поэтому автократы стремятся искусственно завысить ее показатели [4].

Еще одна группа, выделяемых нами факторов, основывается на экономических характеристиках муниципалитета.

Следуя за теорией экономического голосования, можно ожидать, что качество жизни в городах влияет на электоральную конкуренцию. Так, М. Джулиани и С. Массари говорят о том, что, если экономика функционирует плохо, то избиратели наказывают того, кто находится у власти, если с экономикой все хорошо, то вознаграждают [17]. В этой связи можно предположить, что при более высоком уровне жизни избиратели будут склонны поддерживать инкумбентов, которые его обеспечили. Также Э. Даунс писал о том, что избиратель будет голосовать за того кандидата или партию, который, по его мнению, предоставит ему больше выгод [16]. С другой стороны, стоит отметить, что богатые территории наименее подвержены манипуляциям во время электоральной гонки, так как у граждан есть требующиеся им ресурсы (что следует из теории политических машин) и, как следствие, выборы могут быть более конкурентными [23].

\section{Метод и данные}

В первую очередь следует определить зависимую переменную в нашей работе, для этого обратимся к такому показателю, как индекс эффективного числа электоральных кандидатов. Индекс эффективности электоральных партий предназначен для определения конфигураций партий, которые участвуют в электоральном процессе [14, с. 135-136], в нашем случае - в городских советах или думах. Расчеты были проведены на основе результатов последних выборов в представительные органы Кирова (2017 г.), Уфы (2016 г.), Перми (2016 г.), Нижнего Новгорода (2015 г.), Йошкар-Олы (2014 г.), Тольятти (2018 г.), Ижевска (2015 г.), Чебоксар (2015 г.), Оренбурга (2015 г.), Ульяновска (2015 г.), Саратова (2016 г.), Казани (2015 г.), Пензы (2014 г.), Набережных Челнов (2015 г.) и Саранска (2016 г.) (рис.). За основу брались результаты голосования по мажоритарной части. Если рассматривать мажоритарную часть, то она наиболее показательна, так как присутствует наличие личной связи кандидата и избирателя, а также территории. Поэтому, как предполагают П. Панов и К. Росс, изучающие конкуренцию на региональном уровне, конкурен-

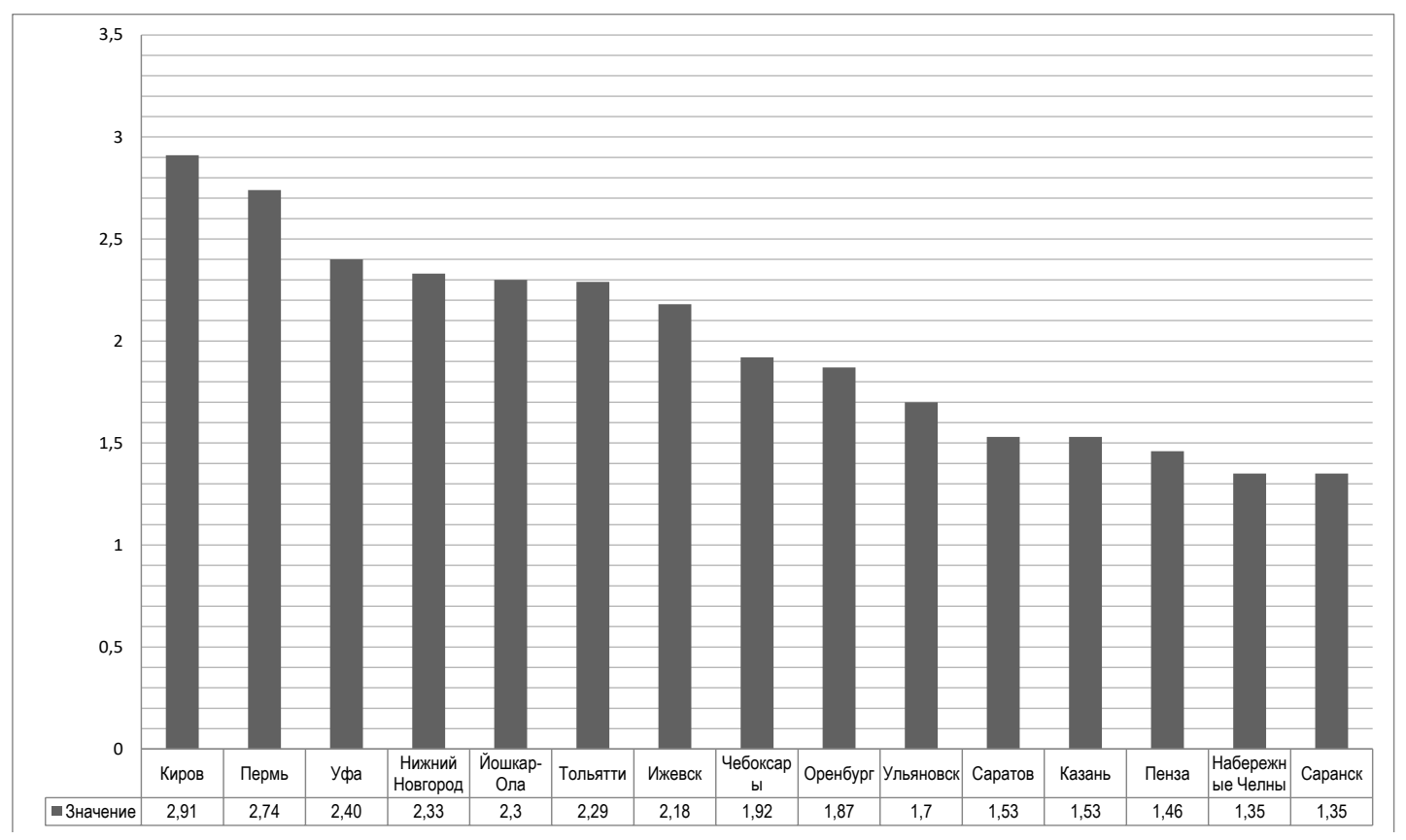

Рис. Уровень конкуренции в городах ПФО 
ция по мажоритарной части выше, чем по пропорциональной [22]. Индекс эффективного числа электоральных кандидатов рассчитывался по формуле Г. Голосова. В отличие от индекса ЭЧЭК Лааксо и Таагеперы [20], который обладает некоторой прогностической функцией, индекс Г. Голосова [9] отражает реальную ситуацию на конкретный момент времени и работает в случаях наличия в системе доминирующей партии [14].

Данные для расчетов были взяты с сайта Центральной избирательной комиссии Российской Федерации [13]. Таким образом, полученные данные можно разделить на две группы:

1. Высокий уровень конкуренции: Киров, Пермь, Уфа, Нижний Новгород, Йошкар-Ола, Тольятти, Ижевск;

2. Низкий уровень конкуренции: Чебоксары, Оренбург, Ульяновск, Казань, Саратов, Пенза, Набережные Челны, Саранск.

Под высоким уровнем конкуренции в данном случае понимается такая конкуренция, значение которой по вычисленному индексу больше 2. В другом случае, наоборот: там, где значение ниже 2 , конкуренция низкая.

Вторым этапом после определения зависимой переменной следует обозначить независимые переменные, которые в дальнейшем будут использоваться в Qualitative Comparative Analysis (QCA). Сам метод качественного сравнительного анализа предполагает выявление закономерностей, которые обусловливают наличие того или иного феномена, который интересен исследователю. В данной работе используется метод QCA, так как он эффективен в анализе малого и среднего количества случаев [1].

Исходя из теоретической рамки, было сформулировано пять независимых переменных: этнический состав, качество жизни населения в городах, повторное выдвижение инкумбентов, явка на выборы и население пенсионного возраста. Данные об этническом составе населения городов и данные о населении старше трудоспособного возраста были взяты с региональных сайтов всероссийской переписи населения 2010 года. В исследовании была учтена доля этнического населения в городах. Индекс качества жизни использовался из исследования Финансового университета при Правительстве РФ, которое проводилось в 2018 году. [12] Выдвижение инкумбентов отслеживалось посредством анализа баз ЦИК РФ. В работе был учтен процент инкумбентов, которые повторно участвовали в рассмотренных нами выборах. Также на сайте ЦИК РФ были взяты данные по явке на выборы в муниципалитетах с 20122018 года, в работе использовался среднее арифметическое от явки на всех выборах в данный период времени в каждом городе.

Качественный сравнительный анализ был проведен с помощью программы Tosmana, которая подразумевает бинарное кодирование переменных. В кодировании зависимой переменной 1 - выраженная конкуренция двух или более партий, 0 - отсутствие конкуренции. Таким образом, были сформулированы предположения относительно уровня конкуренции:

1. Если доля этнического населения высока, то наблюдается низкая конкуренция.

1. Там, где качество жизни находится на высоком уровне, наблюдается высокий уровень конкуренции.

2. Наличие большого числа инкумбентов в предвыборной гонке снижает уровень конкуренции.

3. Чем выше явка на выборах, тем ниже уровень конкуренции.

4. В тех городах, где значительная часть населения является пенсионерами, уровень конкуренции низкий.

Переменные были закодированы таким образом:

- Ethnic: пороговое значение 50\%, 1 - менее $50 \%$ русского населения, 0 - более $50 \%$ русского населения; 
- Quality: пороговое значение 51,46 (среднее значение по городам ПФО), меньше 51,46-0 - низкий уровень жизни, 1-больше 51,46., высокий уровень жизни;

- Incumbent: пороговое значение $50 \%, 0$ - в менее чем 50\% мажоритарных округов выдвинуты инкумбенты, 1 - в более чем 50\% мажоритарных округов выдвинуты инкумбенты;

- Turn out: пороговое значение $36,46 \%$ (среднее значение явки по всем мажоритарным округам ПФО в период с 2014 по 2018 гг.), 0 - явка низкая \ниже средней, 1 - явка высокая/выше средней;

- Age: пороговое значение 21,51\% (среднее число людей пенсионного возраста по мажоритарным округам ПФО), 0 - менее $21,51 \%$ населения пенсионного возраста, 1 - более 21,51\% населения пенсионного возраста;

- Competition: пороговое значение 2 (среднее эффективное число кандидатов по всем мажоритарным округам, рассчитанное по формуле Голосова), 0 - нет конкуренции (значение менее 2), 1 - есть конкуренция (значение больше 2).

Результат кодирования представлен в таблице, которая указана в таблице.

\section{Анализ данных}

В самом начале стоит отметить, что качественный сравнительный анализ не дал единой формулы, описывающей все случаи высокой конкуренции в наших кейсах. Вероятно, это связано с малым количеством переменных, а также с исключением из анализа ряда переменных из-за отсутствия данных (уровень диверсификации экономики в муниципалитетах, размерах избирательных фондов кандидатов и т.д.). При этом выделен определенный паттерн, объясняющий высокий уровень конкуренции, для таких городов, как Киров, Ижевск и Йошкар-Ола:

Ethnic $\{0\} *$ Quality $\{1\} *$ Incumbent $\{0\} *$

Turn out $\{0\} *$ Age $\{0\}+$

Ethnic $\{0\} *$ Quality $\{0\} *$ Incumbent $\{0\} *$

Turn out $\{0\} *$ Age $\{1\}$

Из данной формулы можно сделать вывод о том, что в обоих сочетаниях условий

Таблицุа

Итоговая таблица кейсов и переменных

\begin{tabular}{|c|c|c|c|c|c|c|}
\hline & Ethnic & Quality & Incumbent & Turn out & Age & Compet \\
\hline Ufa & $48,86 \%(1)$ & $59(1)$ & $33,33 \%(0)$ & $42,79 \%(1)$ & $20,16 \%(0)$ & $2,40(1)$ \\
\hline Perm & $90,68 \%(0)$ & $51(0)$ & $72,73 \%(1)$ & $27,73 \%(0)$ & $22,13 \%(1)$ & $2,74(1)$ \\
\hline NN & $95,12 \%(0)$ & $44(0)$ & $62,86 \%(1)$ & $22,46 \%(0)$ & $24,53 \%(1)$ & $2,33(1)$ \\
\hline Oren & $83,24 \%(0)$ & $49(0)$ & $45 \%(0)$ & $21,70 \%(0)$ & $19,74 \%(0)$ & $1,87(0)$ \\
\hline Penza & $92,94 \%(0)$ & $51(0)$ & $65,71 \%(1)$ & $19,47 \%(0)$ & $24,11 \%(1)$ & $1,46(0)$ \\
\hline Tol & $86,15 \%(0)$ & $38(0)$ & $94,44 \%(1)$ & $25,63 \%(0)$ & $21,15 \%(0)$ & $2,29(1)$ \\
\hline Sarat & $86,93 \%(0)$ & $41(0)$ & $50 \%(1)$ & $53,75 \%(1)$ & $25 \%(1)$ & $1,53(0)$ \\
\hline Kazan & $48,63 \%(1)$ & $66(1)$ & $32 \%(0)$ & $61,35 \%(1)$ & $22,04 \%(1)$ & $1,53(0)$ \\
\hline Nch & $44,87 \%(1)$ & $55(1)$ & $22,73 \%(0)$ & $69,77 \%(1)$ & $17,74 \%(0)$ & $1,35(0)$ \\
\hline Izh & $71,98 \%(0)$ & $54(1)$ & $47,62 \%(0)$ & $23,65 \%(0)$ & $20,38 \%(0)$ & $2,18(1)$ \\
\hline Ul & $77,65 \%(0)$ & $46(0)$ & $50 \%(1)$ & $27,66 \%(0)$ & $22,29 \%(1)$ & $1,7(0)$ \\
\hline Yosh & $66,55 \%(0)$ & $58(1)$ & $46 \%(0)$ & $20,42 \%(0)$ & $20,99 \%(0)$ & $2,3(1)$ \\
\hline Saran & $66,13 \%(0)$ & $57(1)$ & $43 \%(0)$ & $71,38 \%(1)$ & $21,93 \%(1)$ & $1,35(0)$ \\
\hline Cheb & $33,64 \%(1)$ & $55(1)$ & $76 \%(1)$ & $39,11 \%(1)$ & $17,72 \%(0)$ & $1,92(0)$ \\
\hline Kirov & $96,65 \%(0)$ & $48(0)$ & $39 \%(0)$ & $20,04 \%(0)$ & $22,77 \%(1)$ & $2,91(1)$ \\
\hline
\end{tabular}


этнический состав влияет на конкуренцию: в регионах с преобладанием русского населения конкуренция выше. Также отсутствие инкумбентов позволяет открыть арену для политической конкуренции. Вследствие чего происходит смена локальных элит. В обеих комбинациях условий наличие конкуренции включает в себя условие низкой явки. С другой стороны, стоит отметить, что переменные качество жизни и наличие пенсионного населения в данном случае не имеют особого значения.

Рассмотрим исход 0, который обозначает отсутствие конкуренции. Полученная формула описывает кейсы Казани, Саранска, Саратова и Чебоксар:

$$
\text { Quality }\{1\} * \text { Incumbent }\{0\} * \text { Turn out }\{1\}
$$$$
\text { * Age }\{1\}+
$$

Ethnic $\{0\} *$ Quality $\{0\} *$ Incumbent $\{1\} *$

Turn out $\{1\} *$ Age $\{1\}+$ Ethnic $\{1\} *$ Quality $\{1\} *$ Incumbent $\{1\} *$ Turn out $\{1\}$

$$
\text { * Age }\{0\}
$$

Из этой формулы следует, что высокое качество жизни в двух из трех сочетаний обусловливает отсутствие конкуренции, а не ее повышение, как ожидалось. При этом наличие большей доли населения пенсионного возраста подтверждается в двух из трех случаев. Наличие большой доли инкумбентов на выборах сыграло роль в двух сочетаниях и привело к низкой конкуренции. Единственная переменная, которая присутствует во всех сочетаниях - высокий уровень явки на выборах.

Помимо формул, объясняющих высокую и низкую конкуренцию, существуют и противоречивые случаи, которые указывают на то, что все переменные, которые мы использовали в анализе, не могут однозначно объяснить наличие или отсутствие конкуренции в рамках всей выборки. Например, в таких случаях, как Пермь, Нижний Новгород, в которых присутствует конкуренция, Пенза и Ульяновск, в которых конкуренция отсутствует, играет роль наличие большей части инкумбентов зарегистрированных на выборах, а также наличие большой доли населения пенсионного возраста. В других случаях: Уфа, в которой выборы конкуренты, и Набережные Челны, в которых выборы неконкурентны, - имеют значение оставшиеся переменные, то есть наличие этнического населения, высокая явка на выборах и высокий уровень качества жизни.

\section{Заключение}

Проведенный анализ не включил в себя ряд независимых переменных, которые согласно теоретическим ожиданиям, могли оказаться значимыми для объяснения уровня конкуренции. Это объясняется с труднодоступностью данных, например, касающихся диверсификации экономики. При этом в анализ были включены такие переменные, как наличие этнического населения, качество жизни, количество участвующих инкумбентов, явка и наличие населения пенсионного возраста.

Проведенный качественный сравнительный анализ частично подтвердил предположения о том, что работа политических машин, основанных на преобладании этнического населения, способствует низкой конкуренции. Утверждение о том, что высокая явка обусловливает низкий уровень конкуренции на выборах, также получило подтверждение. Вероятно, высокий уровень явки мог быть искусственно завышен с помощью фальсификаций и или мобилизации. Анализ позволил укрепить представление о том, что большое количество инкумбентов на выборах, приводит к тому, что выборы становятся менее конкурентны. Предположение о роли качества жизни в повышении конкуренции является спорным. В случае с низкой конкуренцией можно предположить, что поддержка инкумбентов обусловливается теорией экономического голосования, так как уровень жизни в получившемся паттерне является высоким. Из чего следует, что в городах с развитой экономикой избиратели будут поддерживать инкумбентов. 
Также нет ясных подтверждений того, что наличие большой доли населения пенсионного возраста вносит вклад в устойчивость политических машин и затрудняет конкуренцию. В случаях наличия конкуренция и в случаях ее отсутствия встречается большая доля населения пенсионного возраста.

Стоит также отметить, что значительная часть исследуемых кейсов попала в группу, так называемых «противоречивых случаев», когда одни и те же сочетания условий ведут к разным исходам. Это может быть связано с тем, что в ходе исследования не были учтены значимые переменные.

Повысить релевантность результатов позволит расширение выборки и применение иного метода анализа, например, регрессионного. Также, вероятно, сыграло роль наличие малого количества переменных в анализе. Проблему может решить более глубокое описание противоречивых случаев, чтобы понять, какие переменные были упущены в ходе анализа. Данный вопрос требует последующего более глубокого исследования.

\section{Библиографический список}

1. Бесплатная интернет-библиотека. Качественный сравнительный анализ. Сущность метода Качественный сравнительный анализ (Qualitative Comparative Analysis) [Электронный pecypc] URL: $\quad$ http://pdf.knigi-x.ru/21 fizika/304548-1-102-kachestvenniy-sravnitelniy-analiz-suschnost-metodakachestvenniy-sravnitelniy-analiz-qualitative-compar.php (дата обращения: 16.02.2019).

2. Воронцов В.С. Роль этнического фактора в выборной кампании депутатов Государственной Думы Федерального Собрания Российской Федерации шестого созыва // Антиномии: Научный ежегодник Института философии и права УрО РАН. - 2012. - № 12. - С. 389-393.

3. Гельман В.Я. «Столкновение с айсбергом»: формирование концептов в изучении российской политики // Полис. Политические исследования. - 2001. - № 6. - С. 6 - 18.

4. Гельман В.Я. От «бесформенного плюрализма»-к «доминирующей власти»? (Трансформация российской партийной системы) // Общественные науки и современность. - 2006. - № 1. - С. 46-58.

5. Гельман В., Рыженков С., Белокурова Е., Борисова Н. Реформа местной власти в городах России, 1991-2006. - СПб.: Норма, 2008. - 368 с.

6. Голосов Г.В. Честность выборов и явка избирателей в условиях авторитаризма // Политическая наука. - 2019. - № 1. - С. 67-89.

7. Любарев А.Е. Активность избирателей на федеральных, региональных и муниципальных выборах в Российской Федерации // Социодинамика. - 2013. - № 8. - С. 138-209.

8. Министерство финансов РФ. Расчет распределения дотаций на выравнивание бюджетной обеспеченности между субъектами Российской Федерации на 2018 год и плановый период 2019 и 2020 годов [Электронный ресурc] - URL: https://www.minfin.ru/ru/ (дата обращения: 05.03.1019).

9. Полит.ру. Голосов Г.В. Мир партийных систем и партийные системы мира [Электронный ресурс] URL: https://polit.ru/article/2011/04/06/partyism/ (дата обращения: 25.03.2019).

10. Пшеворский $A$. Демократия рынок. Политические экономические реформы Восточной Европе, Латинской Америке: пер. англ. / под ред. проф. Бажанова В.А. - М.: «Российская политическая энциклопедия» (РОССПЭН), 2000. - 320 с.

11. РИАРЕЙТИНГ. Россия Сегодня [Электронный ресурс] - URL: http://riarating.ru/infografika/20180523/630091878.html (дата обращения 05.03.2019).

12. Российская газета. Качество жизни в городах России [Электронный ресурс] - URL: https://rg.ru/pril/article/162/11/08/73._Kachestvo_zhizni_v_gorodah_Rossii.pdf (дата обращения: 07.01.2019)

13. Центральная Избирательная комиссия РФ. Сведения о проводящихся выборах и референдумах [Электронный pecypc] - URL: http:/www.vybory.izbirkom.ru (дата обращения 23.12.2018).

14. Шиагин C.A. Региональные партийные системы в современной России: к методологии исследования // Вестник Томского государственного университета. Философия. Социология. Политология. - 2012. - Т. 19. - № 3. - С. 134-142.

15. Domofond.ru. Полный рейтинг городов России по качеству жизни в 2018 году [Электронный ресурс] URL: https://www.domofond.ru/statya/polnyy_reyting_gorodov_rossii_po_kachestvu_zhizni_v_2018_ godu/7679 (дата обращения 12.01.2019).

16. Downs A. An Economic Theory of Democracy // Midwest Journal of Political Science. - 1957.

17. Giuliani M., Massari S. The economic vote at the party level: Electoral behaviour during the Great Recession // Party Politics. - 2017. - Vol. 49. - № 4. - P. 461-473.

18. Hale H. Explaining machine politics in Russia's regions: Economy, ethnicity, and legacy // Post-Soviet Affairs. - 2003. - № 3. - P. 228-263. 
19. Hale H. Why not parties in Russia? Democracy, federalism and the state. - Cambridge: Cambridge university press, 2006. $-275 \mathrm{p}$.

20. Laakso M., Taagepera R. The «Effective» Number of Parties: A Measure with Application to West Europe // Comparative Political Studies. -1979.

21. Mair P. Party System Change: Approaches and Interpretations. - Oxford: Clarendon press, 1998. $-264 \mathrm{p}$.

22. Panov P., Ross C. Patterns of Electoral Contestation in Russian Regional Assemblies: Between Competitive and Hegemonic Authoritarianism // Demokratizatsiya. - 2013. - Vol. 21. - № 3. - P. 369-399.

23. Stokes S. Perverse Accountability: A Formal Model of Machine Politics // American Political Science Review. - 2005. - Vol. 99. - № 3. - P. 315-325.

\title{
THE FACTORS OF COMPETITION IN MUNICIPAL ELECTIONS BY EXAMPLE OF THE VOLGA FEDERAL DISTRICT CITIES
}

\author{
U.I. Chadova
}

\section{Perm Federal Research Centre UB RAS}

The purpose of the article is to identify the factors that determine the presence or absence of competition in municipal elections. The paper summarizes the theoretical material on the phenomenon of competition at the federal, regional and municipal levels. The formulated theoretical framework allowed to identify such factors as quality of life, ethnic composition of population, the proportion of age retirement population, the share of registered incumbent candidates in the elections. The main content of the research is a qualitative comparative analysis (QCA). The results of elections to the representative bodies of the largest urban districts and municipal districts of the Volga Federal district during the last electoral cycle were analyzed. The analysis determined that the presence of political machines in the territories with a predominance of ethnic population contributes to low competition. The paper also confirmed the claims that the high turnout, the predominance of candidates-incumbents in the elections causes a low level of competition in the elections. The assumption of the role of quality of life in increasing competition is controversial, because it has not received a certain result during the work. At the same time, the identified factors are ambiguous, as due to the limited empirical data, significant variables were probably not taken into account.

Keywords: municipalities, elections, competition.

\section{Сведения об авторе}

Чадова Ульяна Игоревна, лаборант отдела по исследованию политических институтов и процессов, Пермский федеральный исследовательский центр УрО РАН (ПФИЦ УрО РАН), 614900, г. Пермь, ул. Ленина, 13A; e-mail: ulyana.chadova@gmail.com 